\title{
Dobbelary: Om van baie verloorders te maak en van min wenners?
}

D P Veldsman

\author{
ABSTRACT
}

Gambling: Making losers of many and winners of few?

The question of the desirability of legalising gambling in South Africa and the affirmative proposal by the Howard Commission Report (March 1993) to this extent, is critically addressed in this short paper. Gambling, being a game of chance - and certainly already a well established and favourite pastime in South Africa - invites an understanding of the element of chance. A philosophical understanding of this everchanging and enchanting element of everyday life, tells more about the worldviews of those that are interpreting the element of chance than of the element of chance itself It is therefore necessary to address the distinctive responsibilities of the church and especially the state with regard to legalising games of chance as well as reflecting on probable societal implications.

\section{INLEIDING}

Met 'n verwettigde staatslotery in ons land voor die deur en dobbelary daaragter om Trappies en Voëltjie van TV 1 se bekende spreekwyse te leen - is enkele tot stilstand bringende vrae tog van pas. Vrae wat dalk net 'n bietjie (filosofies) dieper kan sny as die haastig-oppervlakkige afkeur/goedpraat van dobbelary. Nie goedkoop vrae nie, maar vrae soos: Wat is die aard van dobbelary as "spel"? Waar kom dit vandaan? Hoe moet ons die kanselement wat koggelend-uitnodigend en belustigend-vry hiervan deel is, verstaan? Hoe moet die kanselement (waarop o a die hele versekeringsbedryf en aandelebeurs op verskillende wyses en met verskillende oogmerke berus) binne hierdie konteks verstaan word? Wat is reeds die omvang van dobbelary in ons land? Wat is die argument vir die verwettiging van 'n staatslotery? Wie sal die meeste wen - of verloor - indien staatslotery verwettig word? Is die verwettiging 'n goeie, oortuigende of kortsigtige argument waarin slegs uiteindelik na die (kortsigtige) belange (welsyn?) van die staat omgesien word? Wie dra die uiteindelike sosiale verantwoordelikheid? Wie sien na die sekondêre gevolge van dobbelary om? Waar pas die kerke en hulle afkeur hieraan in? Of pas hulle nêrens in nie?

Nie al hierdie vrae sal hier afdoende beantwoord kan word nie. Hierdie kort bespreking wil alleen enkele argumentatiewe lyne aansny. Die skrywer hiervan 
het ook nie al die antwoorde nie. Ten minste kan 'n aantal argumentatiewe kaarte gespeel word. Om 'n "hemelse Joker" by voorbaat te speel as verbod op dobbelary (dit wil sê die sogenaamde ongeoorloofde spel met die geluksgod), mag egter uiters oninsigtelik-prematuur en/of onverantwoordelik wees, want ook geloof en geloofsgebruike (byvoorbeeld die werp van die lot) het die kanselement onvermydelik as struktuurelement.

Dobbelary is 'n spel van kans. Eerstens gaan gevra word na hierdie kanselement; daarna na die aard van spel/speletjies, dobbelary as spel, die herkoms en voorkoms van die spel in Suid-Afrika en ten slotte 'n voorlopige etiese oordeel daaroor.

\section{KANS}

Die beroemde Griekse atomis Demokrites (460-370 vC) wat die atoomteorie van die vyfde eeuse Leukippes in detail uitgewerk het, het aangevoer dat die kosmos/wêreld deur kans georden is1. Vir hom het dit beteken: Die wêreld het sonder rede of doel (Grieks: maton) uit sigself (auto) ontstaan (automaton). Die woord outomaties ken ons vandag nog baie goed, maar met 'n klemverskuiwing weg vanaf die kanselement en sterker na die betekenis van selfwerksaamheid. Vir die groot Griekse filosoof Aristoteles ("Fisika"), wat in die vierde eeu vC geleef het, was kans (automaton en tuche) "iets" wat "per ongeluk" gebeur. Kans was vir hom onbepaalbaar, veranderlik en onstabiel. Interessant egter voeg hy by dat daar twee tipe kanse is. Die tipe word bepaal deur die blik/belang van die betrokkenes daarop. Die derde eeuse skrywer Aleksander van Aphrodisias het wat Aristoteles hiermee bedoel, so verduidelik: 'n verlore perd word deur sy eienaar gevind. Vir die eienaar is dit "geluk" (tuche, dit wil sê, "good luck"), vir die perd bloot toevallig (automaton). So is dan gepraat van goeie en slegte geluk.

Die nadenke van skrywers en digters oor wat kans is, word gereflekteer in die benaming van die Griekse godin van geluk te wete Tuche, dit is geluk wat van die hemel kom. "Wat van die hemel" kom, was egter nie altyd so gelukbringend vir die mens nie, sodat die woord tuche en moira (lot/noodlot) saamgegooi is. Kans en lot het ten aansien van die "onverklaarbare" van die lewe onskeibare interpretatiewe bedmaats geword.

Die Christelike verstaan van kans - wat hiervan verskil, maar self ietwat varieer - sluit by een van twee interpretatiewe lyne aan ${ }^{2}$ : 6 f by die vierde/vyfde eeuse kerkvader Augustinus uit Noord-Afrika ("Stad van God") of by die dertiende eeuse Italiaanse Rooms-Katoliek Thomas van Aquino ("Summa theologiae"). Vir eersgenoemde was daar geen plek vir kans of geluk nie, aangesien Gods voorsienigheid alles wat gebeur, beheer het. Vir Thomas was daar plek vir kans in voorsienigheid, maar dan ooreenkomstig God se wil. In hierdie twee Christelike interpretasies 
word gepoog om van die heilige handeling van die werp van die lot as gebruik in die geskiedenis van Israel, sin te maak (bv by die verdeling van land tussen die stamme van Israel; die kies van 'n koning; die aanwys van 'n oortreder en in die algemeen vir die bereiking van ' $n$ beslissing) ${ }^{3}$.

Filosofiese besinning oor kans het bontig verloop waarvan hier slegs na enkele denkers verwys sal word ${ }^{4}$. Vir die Skotse filosoof David Hume (1711-76) was daar nie iets soos kans nie. Ons onkunde oor die werklike oorsaak van 'n gebeure het aanleiding tot so 'n opvatting gegee, aldus Hume. Die Duitse filosoof en wiskundige Gottfried Leibniz (1646-1716) het op sy beurt weer gepraat van 'n "gebrek" in ons kennis om kans te verstaan. Charles Pierce (Kans, liefde en logika) verwys na die noodsaaklike teenwoordigheid van kans wat met "reëlmaat" spontaan gebeur. Ook Max Born (Natuurlike Filosofie van oorsaak en kans) het vanuit die hoek van die kwantumfisika (en onder die invloed van Heisenberg se "beginsel van onsekerheid" ten opsigte van atome se beweging) gepraat van "kans wat met sekere reëlmatigheid gemeng" is en die "natuur wat deur die wette van die natuur en die wette van kans" beheer word. Ook in ons eietydse ekonomiese strukture word op verskillende wyses en vanuit verskillende oogmerke erns gemaak met die kanselement, soos byvoorbeeld in die versekerings-bedryf. Hier moet die risiko wat die kanselement teweegbring juis geminimaliseer word ten einde lewenstabiliteit te verseker.

Hoe jy die kanselement verstaan, vertel in die eerste plek meer van jou eie lewens- en wêreldbeskouing as van die onvaspenbare element self. Wanneer jy moet oordeel oor wat kans is en watter rol dit speel, dan word jou oordeel vooraf, dit wil sê voor die tyd reeds, bepaal deur baie spesifieke oortuiginge, byvoorbeeld: is ek 'n religieuse persoon of nie. Indien ek wel 'n religieuse persoon is, is dit goed moontlik dat ek leef met die oortuiging (let wel: ander religieuse oortuiginge is ook moontlik) dat niks aan toeval ("kans") oorgelaat is nie, maar dat alles in Gods voorsienigheid berus. Dit is ' $n$ oortuiging wat "voor" my interpretasie van wat die kanselement is en behels, kom. Selfs die "onskuldige" gebruik van sommige gelowiges om die Bybel te laat oopval by 'n betrokke teksgedeelte, berus - menslik gesproke - op die beginsel van toevalligheid en so dus kans. Dit is egter net so goed moontlik dat ek as "ongelowige/gelowige" vanuit die verstaan van die "onsekerheidsbeginsel" (Heisenberg) van die beweging van subatomiese materiaal die kanselement anders kan verstaan, naamlik as voor-komend met spontane reëlmaat. Die kanselement laat sigself egter nie so maklik in 'n interpretatiewe skema inpas nie. Hoe dit ook al vooraf verstaan word, in dobbelary as spel word kans die meestal ontwykende, maar begeerde en bekorende metgesel. 
Spel/speletjies is 'n sosiale/kultuurhandeling wat die daaglikse roetine van arbeid op die een of ander wyse onderbreek of afwissel${ }^{5}$. Een skrywer sê dat "speel" vanuit die inherente rusteloosheid van die mens voortspruit asook vanuit die noodsaak van die gebruik (ontwikkeling, bewaring) en oefening van die fisiese, mentale en morele kragte.

Die vroegste historiese herkoms van speel/spel is baie onduidelik, alhoewel dit heel waarskynlik met sang, dans en rituele (veral seremonies en spesifiek seremonies met religieuse betekenisse) saamgehang het. Speletjies was dikwels 'n onuitgesproke nabootsing of afbeelding van die wêreld ( $\mathrm{d}$ w s 'n kosmologie in die kleine), gebeure of wêreldverstaan (vgl skaak as afbeelding van die stryd tussen goed en sleg).

Spel ("games") is 'n ordelike, herhalende, en meestal georganiseerde "besigwees" deur een/twee of meer persone. Hierdie besigwees het as primere oogmerk die intensie van plesier of tydverdryf deur middel van die vertoon van vaardighede of goeie geluk van die speler(s). Die besigwees verloop volgens bepaalde reëls en somtyds is spesiale apparatuur/instrumente nodig.

Drie tipes - alhoewel ook mengtipes hiervan voorkom - kan in die breë onderskei word: speletjies wat (a) op vaardighede berus, byvoorbeeld fisiese, mentale of morele vaardighede; (b) op nabootsing berus (byvoorbeeld drama, voordrag) en (c) op geluk berus. Hier is my belang by die laaste tipe spel.

Speletjies wat op geluk berus, hou waarskynlik histories baie nou verband met wyses waarop waarsêery/voorspelling plaasgevind het. Die speletjies self is waarskynlik 'n gesekulariseerde vorm van voorspelling, maar om belangstelling hierin te verhoog, het dit gepaard gegaan met een of ander vorm van weddenskap. Baie ou voorbeelde hiervan vertel van die Noord-Amerikaanse Indiane wat weddenskappe aangegaan het oor die kleure van pitjies of klippe; die Siamese oor na watter kant (na bo of na onder) die opening van 'n mossel sou vorm; in Homerus se tyd het die Grieke alreeds dobbelsteentjies (aan vier kante gemerk) gehad, gemaak van die skenkelbeendere van skape/beeste. Eers later word dobbelsteentjies wat aan ses kante gemerk is, gevind. Dit was goed bekend in die latere Egiptiese en Romeinse ryke. In Oosterse literatuur is daar verskeie verwysinge na dobbelary asook na die streng verbod daarop 6 .

J L Paton maak die interessante opmerking oor die voorkoms van dobbelary in die vroegste tye, naamlik dat dit veral voorgekom het in samelewings waar mense 'in minder stabiele lewenspatroon gehad het (bv: jagters, soldate, handelsreisigers). 'n Passie om hulle lewenspatrone te kon verander met een strepie/skoot van geluk, het 'n voortwoekerende passie geword. Hiermee het die motiewe vir 
dobbel direk verband gehou: die begeerte na meer, na opwinding en na oorwinning?.

Nou moet ons 'n sprong maak vanaf hierdie vroegste voorkoms van dobbelary tot die voorkoms daarvan in Suid-Afrika.

\section{OMVANG VAN DOBBELARY IN SUID-AFRIKA}

Die omvang en geldelike omset van dobbelary in Suid-Afrika - soos uiteengesit in die verslag van die Howardkommissie van Maart 1993, is verbysterend8: 'n Jaarliks konserwatief-geraamde skatting van meer as R8 biljoen. Perderesies ( \pm R3,1 biljoen), Fah-fee (R2-5 biljoen), Casino's, birne en buite Suid-Afrika se landsgrense, (byna R2 biljoen), krapkaarte (w o Operation Hunger, Community Chest, Viva, Ithuba, Natal Lotto; 'n omset van R265 miljoen). Baie ander informele vorme kom ook voor wat hier nie in berekening gebring is nie (byvoorbeeld: "raffles" van verskillende instansies soos skole, klubs en kerke). Tereg kan hierdie verslag die konklusie trek dat dobbelary in Suid-Afrika reeds 'n gevestigde bedryf is en 'n "popular pastime". Indien hierdie bedryf reeds so gevestig is, waarom dit nou verwettig?

\section{ARGUMENT TOT VERWETTIGING VAN DOBBELARY}

Die argument wat die verwettiging van dobbelary (in besonder met die oog op 'n staatslotery) moet regverdig, is die volgende:

Ten einde ekstra inkomste te genereer vir behuising, onderwys en ander welsynaksies waarin die staat nie op voldoende wyse kan voorsien nie, kan 'n staatslotery ingestel word sodat die geld wat hieruit gemaak word vir hierdie doel aangewend kan word. Die enigste ander wyse waarop die staat inkomste kan genereer is deur belasting verder te verhoog?.

Op die uitnodiging van die Howardkommissie om voor 30 November 1992 kritiek en voorstelle ten opsigte van gewettigde dobbelary voor te lê, het geen groot kerklike liggaam in Suid-Afrika amptelik-skriftelik in protes reageer nie. Weliswaar is briewe van protes wat op teologies-etiese beginsels berus, ontvang van die Metodiste-gemeente van Richmond, die Gereformeerde Kerk van Vaalharts, die Ned Geref Kerk Floraunapark (Pretoria), die "Salt Shakers" ('n klein christelike organisasie) en 8 indiwidue. Dr D F Theron het namens die Algemene Kommissie vir die Diens van Barmhartigheid van die Ned Geref Kerk voor die kommissie in persoon verskyn. Watter kritiek en teenargumente is aangevoer? 


\section{TEENARGUMENTE}

Alhoewel die Ned Geref Kerk teologies-eties - soos ook baie ander christelike kerke - dobbelary afkeur, het dr Theron van die Ned Geref Kerk nie dobbelary op hierdie gronde voor die Howardkommissie opponeer nie, maar wel op sosiale gronde (byvoorbeeld misbruik, gebrek aan kontrole).

Die respons van hierdie verslag hierop en op ander se kritiek, is kort en kragtig. Enersyds: diegene wat die verwettiging van dobbelary teenstaan op grond van geloofsbesware se standpunt word gerespekteer. Daar word vertrou dat diegene nooit aan enige vorm van dobbelary sal deel hè nie. Die verwettiging van dobbelary sal diegene ook dus nie raak nie, aangesien niemand gedwing word om daaraan deel te neem nie. Andersyds: gegewe die omvang van dobbelary in Suid-Afrika, kan sonder vrees vir teenspraak daarop gewys word dat miljoene Suid-Afrikaners reeds lustig hieraan deelneem ${ }^{10}$.

\section{OORDEEL}

Die onvaspenbare, maar bekoorlike kanselement as sodanig is 'n onvermydelike deelelement van die menslike lewe. Dobbelary is 'n spel waarin hierdie element blywend uitgenooi en uitgedaag word op 'n persoonlike vlak tot (kits)geluk - of ongeluk. Dit is dus 'n spel wat verantwoordelikheid meebring aangesien die element van kans en die bevoordeling van kans in hierdie spel, onvoorspelbaar gunstig of ongunstig kan uitval tot goeie of slegte nagevolge van die speler (en mense betrokke by hierdie speler). Wie dra hierdie verantwoordelikheid? Is dit net die speler?

Die Howardkommissie het met reg daarop gewys dat geeneen gedwing word om hieraan deel te neem nie en dat die kerk se taak na gelang van haar oordeel is om haar gemeentelede daarop te wys om nie hieraan deel te neem nie. $\mathrm{Na}$ my oordeel is dit hoe die gewetenstaak van die kerk behoort te funksioneer en hoe ver die kerk se taak strek. As die kerk egter op die staat se magsbasis wil aanspraak maak om mense te vervolg wat wel hieraan deelneem, dan "mis"-bruik die kerk die magsbasis van die staat om sy gewetensoordeel op 'n samelewing - wat reeds lustig dobbel - af te dwing. Dit kan en mag doodgewoon nie gebeur in 'n demokrasie wat roem op menslike vryheid nie - al is dit 'n ontnugterende ervaring vir die kerke wat vroeër in Suid-Afrika met direktheid en gemak van die staat se magsbasis gebruik kon maak om hulle eie teologies-etiese oordele op 'n samelewing af te dwing. As die kerk sê Christene moenie dobbel nie, dan moet hulle nie dobbel nie. Dit is die verantwoordelikheid wat die kerk het in die verkondiging van die evangelie. 
Die vraag na verantwoordelikheid wat ook direk aan die staat gerig moet word, is egter nog nie beantwoord nie. Die antwoord van die Howardkommissie op die vraag na die wenslikheid al dan nie van die verwettiging van dobbelary is kort en realisties:

Wetgewing om dobbelary hok te slaan word nie behoorlik toegepas nie en boonop omvangryk geïgnoreer. Die wydverspreide voorkoms en vraag na dobbelary bring mee dat hierdie kommissie van oordeel is dat dit beter is om hierdie vraag na dobbelary te respekteer en te verwettig ten einde aan redelike aanvraag te voldoen. Hierdie toegewing moet onderworpe wees aan beheer en beperkinge ten einde buitensporige misbruik en persoonlike skade te ontmoedig. Terselfdertyd moet kriminele aktiwiteite wat hiermee onvermydelik saamgaan, verhoed word. Die verwettiging van dobbelary moet op so ' $n$ wyse gereël word dat 'n substansiële bydrae tot sosiale opheffing en ekonomiese ontwikkeling gemaak word ${ }^{11}$.

Enkele kritiese opmerkinge ten opsigte van die staat se verantwoordelikheid is hier ten slotte van pas:

- In Amerika is staatsloterye reeds in 33 state verwettig. Dieselfde argument wat deur die Howardkommissie as motivering tot verwettiging aangevoer word, het ook in die onderskeie Amerikaanse state die mees beduidende rol gespeel. In Florida en Kalifornië is egter gevind dat dobbelaars nie goeie fortuinvertellers is nie. Die aantreklikheid van inkomste uit verwettigde dobbelary het onoorkomelike probleme teweeggebring. Oor wat spesifiek hierdie probleme was wat veral die onderwys soos aangedui deur Joe Atkins - baie nadelig getref het, kan hier ongelukkig nie in meer besonderhede behandel word nie 12 .

* Wie dra die verantwoordelikheid van die sekondêre gevolge (verskillende vorme van kriminaliteit, egskeidings wat direk verband hou met eksessiewe dobbelary, selfmoord, bankrotskappe ens) van die verwettiging van dobbelary? Dié verskynsel het - so word reeds beweer in die Amerikaanse state - so omvangryk geword het dat die finansiële hokslaan van die sekondêre gevolge eersdaags die primêre inkomste sal oorskrei ${ }^{13}$.

* Indien die sekondêre gevolge mettertyd die kortsigtige gewin van die staat sou oorskrei, is die vraag hoe hierdie losgelate, uitbundige en verwettigde kansmonster dan hokgeslaan moet word? In die uiterste ekonomiese omstandighede van SuidAfrika is dit ' $n$ baie wesenlike probleem juis omdat dit so ' $n$ buitensporige intensiteit van drome "in a rough country" kan loslaat.

* Indien die sekondêre gevolge die primêre oogmerk kan verongeluk, is die vraag: is 
die onderliggende en onuitgesproke antropologiese oordeel van die verwettiging van dobbelary - in besonder staatslotery - moreel aanvaarbaar, naamlik om van mense verloorders te maak? Is dit nie dalk op die langtermyn die enigste waarborg wat ons het ten opsigte van 'n staatslotery nie, naamlik dat min wen maar baie verloor?

- Hiermee saam: is 'n staatslotery nie 'n onaanvaarbare wyse om die reeds gekommodifiseerde mens nog verder te kommodifiseer deur hulle te degradeer tot 'n ekonomiese "fast food" entiteit ten aansien van die behoeftes van die samelewing nie - soos deur die regering bepaal of voorgeskryf? Word hierdeur nie van 'n ekonomiese nood 'n psigologies-uitbuitende maar aantreklike deug gemaak nie?

Kortom: in die lig van die uiteensetting van die kanselement en die besondere nievaspenbare bekoring daarvan, is dit na my oordeel 'n baie legitieme vraag of verwettigde dobbelary (ingesluit 'n staatslotery) nie 'n "Pandora's Box" oopmaak waarvan enkele implikasies reeds duidelik in die Amerikaanse samelewing deurslaan nie. Indien dobbelary verwettig word op grond van die reeds plesierige omvang daarvan en aanvraag daarvoor, wie dra daarna die verantwoordelikheid met betrekking tot die hokslaan van moontlike sekondere uitlope. Mag die staat dan sy skouers optrek in ontkenning van verantwoordelikheid? Dus: hoe ver strek hierdie verantwoordelikheid van die staat ten opsigte van die welsyn van die samelewing waarvoor die staat teenoor al sy inwoners verantwoordelik is?

\section{NOTAS:}

1 Vergelyk Michiko Yusa, "Chance", in Encyclopedia of Religion, vol 3, 192-6.

2 Vergelyk J L Paton, "Gambling", in Encyclopaedia of Religion and Ethics, vol vi, 163-7. Vergelyk ook E Sidney Hartland, "Games", in Encyclopaedia of Religion and Ethics, vol vi, 167-71.

3 Oor die verbod op dobbelary in die Joods-Christelike (en ook ander godsdienstige) tradisies, vergelyk Paton, $a w, 163 \mathrm{ev;} \mathrm{Alf} \mathrm{Hiltebeitel,}$ "Gambling", in Encyclopedia of Religion, vol 5, 468-74. Kyk J A Heyns, Teologiese etiek, Deel 2/1, Pretoria 1986, 271-2 vir 'n kort uiteensetting van die gronde vir die etiese afkeur van dobbelary.

Vergelyk Yusa, $a w, 193$.

Vir 'n bondige oorsig oor die historiese herkoms en betekenis van spel, vergelyk Hartland, $a$ w, 167 ev; John J MacAloon, "Games", in Encyclopedia of Religion, vol 5, 474-79.

Sien Paton, $a w, 164$; Hiltebeitel, $a w, 469$ vir verdere voorbeelde en verwysing na verskeie tekste in hierdie verband. 
$7 \quad$ Paton, $a w, 164$.

8 Howard Commission Report 1993. My waardering teenoor advokaat J A du Rand van die Departement van Justisie wat op kort kennisgewing hierdie verslag aan my beskikbaar gestel het.

9 Vergelyk die uiteensetting in Howard, $a w, 17-23$.

10 Vergelyk Howard, $a w, 19,22$.

11 Vergelyk Howard, $a w, 22-3$.

12 J Atkins, "The states' bad bet", Christianity Today, 35 (1991) 14, 16-18.

13 Vergelyk hieroor David Neff \& Thomas Giles, "Feeding the monster called more", Christianity Today, 35 (1991) 14, 18-21. 